\title{
Materials used to maintain integrity of enamel in Orthodontics: an update
}

\author{
Pradeep Kandikatla1,*, Sai Sreedevi Kallepalli², Sathya Usha Sree Ravada3 ${ }^{3}$, Pavankumar Chiluvuri ${ }^{4}$ \\ ${ }^{1}$ Reader, ${ }^{2}$ Postgraduate Student, Department of Orthodontics, Vishnu Dental College, Bhimavaram, \\ Andhra Pradesh, India. \\ ${ }^{3}$ Reader, Reader, Department of Orthodontics, Lenora institute of Dental Sciences, Rajahmundry, Andhra \\ Pradesh, India. \\ ${ }^{4}$ Reader, Department of Orthodontics, Konaseema Institute of Dental Sciences, Amalapuram, Andhra \\ Pradesh, India.
}

\section{N F O R M A T I O}

\section{Article History}

Received $1^{\text {st }}$ September 2021

Received revised

$11^{\text {th }}$ November 2021

Accepted $18^{\text {th }}$ November 2021

Available online

$1^{\text {st }}$ December 2021

\section{K E Y W O R D S}

Remineralization

Fluorides

CPP-ACP

Probiotics

Xylitol

Antiseptics

Lasers
After Orthodontic treatment, it's just as crucial to restore a healthy and normal tooth structure as it is to achieve the aims of Orthodontics. Orthodontic treatment has the potential to cause some damage to dental enamel. Orthodontists should make every effort to minimize damage to dental tooth enamel. These enamel lesions, such as white spot lesions, are managed first by developing appropriate dental hygiene habits and prophylaxis with topical fluorides, high-fluoride toothpaste, fluoride mouthwashes, gels, varnishes, fluoride-containing bonding materials, fluoride-containing luting cement, and fluorides in elastomers. Other materials and treatments include casein phosphopeptides-amorphous calcium phosphate, probiotics, carbamide peroxide, polyols, sealants, microabrasion, resin infiltration, antiseptics, and lasers, have recently been recommended. This article reviews the current information regarding the various materials used to manage enamel demineralization and promote remineralization during and after orthodontic treatment.

\section{Introduction}

Restoring a healthy and normal tooth structure after the end of Orthodontic treatment is as important as accomplishing the goals of Orthodontics. If orthodontic therapy is beneficial to the patient, the treatment advantages should significantly outweigh any adverse sequelae that the treatment might cause [1]. The clinician should be aware of the problems during the treatment procedures to prevent, minimize, and manage the possible adverse effects of orthodontic treatment.

Orthodontic procedures such as conditioning and etching of enamel, debonding of brackets, removal of resin debris and resin cement from the enamel surface, and enamel reduction or stripping are a few of the many causes of enamel damage related to iatrogenicity [1]. The presence of fixed orthodontic appliances causes an increasing number of retention sites due to brackets, bands, wires, and other applications making cleaning teeth more difficult [2]. White spot lesions (WSLs) result from prolonged plaque accumulation on the affected surface of the teeth.

Correspondence: ${ }^{*}$ Corresponding author Email Address: pkandikatla@gmail.com

How to cite this article: Kandikatla P, Kallepalli SS, Ravada SUS, Chiluvuri P. Materials used to maintain integrity of enamel in Orthodontics: an update. Int J Dent Mater 2021;3(4): 127-133.

DOI: http://dx.doi.org/10.37983/IJDM.2021.3405 
Enamel damage can be considered an inevitable sequela to orthodontic treatment, with various procedures producing varied effects. Every orthodontic practitioner should aim to minimize injuries to enamel, helping improve the longevity of teeth and dentition as a whole. It necessitates fundamental knowledge of preventive dentistry principles and the clinical skill to apply them properly [2].

Post orthodontic lesion's best course is to wait and watch since most lesions tend to improve their appearance over the first couple of years after debonding [2]. These are managed first by beginning and building on good oral habits and topical fluorides, including high-fluoride toothpaste, fluoride mouthwashes, gels, varnishes, fluoride-containing materials, and elastic ligatures [3].

Recently, other materials and methods, including the use of casein phosphopeptides-amorphous calcium phosphate, antiseptics, polyols, probiotics, sealants, laser, tooth bleaching agents, resin infiltration, and microabrasion [2].

This review intends to compile the most relevant materials and methods that may be useful for healing and maintaining the integrity of the enamel during Orthodontic treatment and post orthodontic treatment.

\section{Remineralization}

One of the essential biological elements determining the intraoral neutralizing effects of acid exposure is saliva. Saliva provides a steady source of calcium and phosphate, which aids in the maintenance of supersaturation with respect to tooth minerals, preventing tooth demineralization during low $\mathrm{pH}$ periods and promoting tooth remineralization when the $\mathrm{pH}$ recovers to neutral [4]. Saliva delivers fluoride to the tooth surface constantly; salivary fluoride is an important factor in avoiding tooth demineralization and promoting remineralization [5]. Visible WSL present after orthodontic treatment tends to decrease in area and improve their appearance over the first couple of years after debonding. The status of the lesions determines the potential for enhancement, with active lesions having an improved prognosis than arrested lesions. Active lesions are more porous and allow for easier penetration of calcium and phosphorous into the enamel during the remineralization process. In contrast, arrested lesions often appear shiny white.
They may even have a brown surface appearance due to the formation of a remineralized layer in the outer part of the enamel. Most WSL that are present after orthodontic treatment have already undergone a demineralization and remineralization cycle. Some of the active lesions at the end of treatment have already been some remineralization as well [6].

\section{Promotion of Remineralization}

\subsection{Fluoride Toothpaste}

Conventional Flouride toothpaste's efficacy $(1,000$ ppm) is contemplated these days; toothpaste with higher fluoride concentrations (1,500-5,000 ppm) have shown a more remarkable ability to inhibit demineralization and promote remineralization. A modified fluoride toothpaste technique involving twice -daily brushing for 2 minutes followed by swishing vigorously with toothpaste slurry for half a minute without rinsing with water, and avoiding eating or drinking for two hours, has also been shown to reduce the incidence of new caries in orthodontic patients [7].

\subsection{Fluoride Rinses}

Daily $0.5 \%$ sodium fluoride rinse and fluoridated dentifrice are perhaps the most common fluoride regimens recommended by orthodontists. For fluoride rinses to be successful in the prevention of WSL, orthodontic patients must use them consistently. Daily mouth rinses with sodium fluoride (NaF) $0.05 \%$ or $0.2 \%$ ) and/or weekly with acidulated phosphate fluoride $(1.2 \%)$ rinse have reduced the prevalence of enamel demineralization during active fixed orthodontic treatment [8].

Benson recommended that the best approach to prevent enamel demineralization during fixed orthodontic treatment is the daily usage of $0.05 \% \mathrm{NaF}$ mouth rinse [9]. Geiger et al. reported a $25 \%$ reduction in the number of WSL using a fluoride rinse. Using $\mathrm{NaF}$ mouth rinse for two weeks, with one rinse per day, had reported a significant increase in fluoride concentration in the saliva [10].

\subsection{Fluoride gel}

Many researchers have tried Stannous fluoride gels $(0.4 \%)$ during orthodontic treatment and reported decreased enamel decalcification. Currently, Boyd compared an 1100 ppm fluoride toothpaste with a daily 0.05 percent $\mathrm{NaF}$ rinse, or a 0.4 percent stannous fluoride gel applied twice daily by a toothbrush to an 1100 ppm fluoride toothpaste alone. [11]. He also 
found that both the gel and rinse provide increased protection against decalcification compared to toothpaste alone, but neither was superior.

\subsection{Fluoride varnish}

Fluoride varnish applied around orthodontic brackets during treatment helps to reduce the extent and prevalence of WSL. Floor protector (1\% difluorosilane and $0.1 \% \mathrm{~F}$ ),Duraphat ( $5 \% \mathrm{NaF})$, duraflor (5\% NaF) are the commonly used Fluoride varnishes. Azarpazhooh concluded that over the 3-year follow-up period, the application of fluoride varnishes every six months was the most cost-effective method for the high- and medium-risk groups [12]. Demito et al. found an increase of $32 \%$ in demineralization in areas where the varnish was not applied compared to a $30-50 \%$ reduction in WSL's in areas where duraphat was applied twice annually [13]. The use of Fluor Protector (polyurethane varnish) decreased WSL formation under molar bands. Recently, chlorhexidine varnishes contemplated reducing plaque accumulation and enamel decalcification.

\subsection{Fluoride-releasing bonding materials}

In the late 1980s, Glass Ionomer cement was replaced as an alternative to the more commonly used composite material for bracket bonding. The proposed benefits of using glass ionomer cement included the lack of need for pretreating the enamel with phosphoric acid to create conditions for mechanical bonding, the release of fluoride over several months, and the possible development of a modified, less cariogenic microflora [14]. The cariostatic effect is mainly attributed to the fluoride release of both glass ionomer and resinmodified glass ionomer cement [15]. It occurred for more extended periods and with greater fluoride release levels than with fluoride-containing composites or compomer cement [15]. Glass Ionomers showed an initial burst of fluoride discharge that rapidly declined to levels that are unlikely to have a clinically significant effect on caries inhibition.

\subsection{Fluoride in luting cements}

It is best to use cement containing fluoride like GIC for banding because fluoride-releasing types of cement such as zinc polycarboxylate and resin-modified GIC shown less enamel demineralization than zinc phosphate cement [16].

\subsection{Fluoride in bonding agents}

Bonding agents, which contain fluoride have the potential for reducing enamel decalcification [17]. Bonding with GIC showed less WSL in 12-year followup in comparison to the conventional composite material. However, traditional fluoride-releasing cement, glass-ionomer cement, and resin-modified GIC have bond strengths that are substantially lower than those of conventional resins. Recently, Bioactive glass (BAG) materials entered the field of dentistry. They are surface-active materials known to successfully release ions (calcium, phosphate, and fluoride ions) in simulated body fluid. Manfred et al. and Brown et al. found that BAG-Bond adhesives outperformed traditional composites to help preserve the superficial enamel hardness around orthodontic brackets and released reservoir ions that decreased the chances of WSL around brackets. As a result, these adhesives could be used as biomimetic bonding agents [18].

\subsection{Fluorides in elastomers}

Fluoride-releasing elastomeric modules have also been shown to effectively minimise plaque accumulation and enamel decalcification around brackets in numerous studies [19]. However, some authors concluded that fluoridated elastomers did not affect the quantity of disclosed plaque around orthodontic brackets. Even the fluoride release from the fluoride-containing elastic chain was high for the 1st week and decreased significantly. Thus, it is good to prescribe Fluoridated toothpaste and mouth rinses so that fluoridated elastomers may imbibe fluoride from their environment [20].

\subsection{Antibacterial adhesives}

The antibacterial activity of 12-methacryloyl-oxydodecyl-pyridinium bromide incorporated in the antibacterial adhesive systems demonstrated inhibition of caries formation, especially along the enamel margins [21]. Among the various metals, silver, since ages, has been known for its antimicrobial activity against various microorganisms. Traditional orthodontic adhesives and appliances have been infused with silver nanoparticles (AgNPs). The antibacterial effects of the silver coating were demonstrated by the decreased adherence of S. mutans and S. sobrinus to the orthodontic brackets. The use of silver nanoparticles on the surface of orthodontic brackets can help to prevent the formation of tooth plaque and cavities during orthodontic therapy [22]. In a study conducted by Wang X, a 
novel RMGIC was developed with NAg for the prevention of white spot lesions. The results of the study showed that RMGIC containing NAg had much stronger antibacterial effects, and the incorporation of NAg into RMGIC could combat white spot lesions both beneath and away from the orthodontic brackets. These advantages were achieved without compromising the enamel shear bond strength and did not require any patient compliance. So, the NAg-containing RMGIC might be more effective in preventing white spot lesions[23].

\subsection{Casein Phosphopeptide-Amorphous Calcium Phosphate}

The role of casein phosphopeptide-amorphous calcium phosphate (CPP-ACP) has helped decrease the incidence of dental caries [24]. The topical anti-cariogenic effect of dairy products in animal and human in situ caries models has led to the production of casein phospho-peptides (CPP) and their accepted ability to stabilize calcium and phosphate in an amorphous state [25]. The CPP molecules contain a cluster of phosphoryl residues which markedly increase the apparent solubility of calcium phosphate by stabilizing amorphous calcium phosphate (ACP) under neutral and alkaline conditions. The localized CPP-ACP nano-complexes subsequently act to buffer free calcium and phosphate ions in the plaque fluid to maintain a state of supersaturation of ACP concerning enamel mineral, thereby limiting enamel demineralization and enhancing remineralization [24].

MI Paste (GC America, Alsip, IL, USA) is a product that contains casein phosphopeptide ACP. This milkderived protein helps to promote high rates of enamel remineralization. MI Paste Plus is the same product as casein phosphopeptide ACP but also has 900 ppm of fluoride. A recent randomized controlled trial demonstrated that patients undergoing orthodontic treatment who used MI Paste Plus nightly along with a fluoride delivery tray for 3 to 5 minutes following brushing showed fewer and less severe WSL than controls [26]. Hence, CPP-ACP might be incorporated into chewing gums, lozenges, or creams. GC marketed it as a cream for application on tooth surfaces twice a day after brushing the teeth and refraining from drinking or eating for $30 \mathrm{~min}$ after the application (Tooth Mousse, Tooth Mousse Plus) (Fluor 900 ppm) [27]. For remineralization post-orthodontic treatment WSLs, CPP-ACP application may be more effective than fluoride rinse.
So, the CPP-ACP's ability to prevent the formation of orthodontic WSLs in the long-term needs elucidation [28].

\subsection{Probiotics}

The use of probiotics has been recently introduced to dentistry. Still, the concept involves populating the oral environment with noncariogenic microorganisms that compete with cariogenic bacteria and periodontal pathogens and reducing their numbers. Although data are scarce on this topic and none specific to WSL prevention, preliminary reports show potential for materials such as ProBiora 3 (Oragenics, Tampa, FL, USA) to positively influence the oral environment reducing S. mutans and specific periodontal pathogens [29]. It is hypothesized that probiotic strains interfere with or inhibit other microorganisms, especially pathogens. Probiotic bacteria might enhance the effect of fluoride in preventing dental caries [30]. The treatment strategies conferred by probiotics are mainly anticipated to be either by inhibition of specific pathogen adhesion, colonization and biofilm formation or by altering the host immune response by inhibition of collagenases, reduction of inflammation-associated molecules [31].

\subsection{Carbamide Peroxide}

Carbamide peroxide, also known as urea-hydrogen peroxide, is a water-soluble, white crystalline solid compound consisting of hydrogen peroxide and urea. There is evidence that urea increases salivary and plaque $\mathrm{pH}$. This increase in $\mathrm{pH}$, together with the antimicrobial effect of hydrogen peroxide, may reduce plaque formation [7]. It enhances patients' compliance with frequent use of carbamide peroxide whitening agents during orthodontic treatment because of the patient's perceived added benefits of tooth whitening.

\subsection{Xylitol}

Polyols are sweeteners that are weakly metabolized (sorbitol) or not metabolized (xylitol) by cariogenic bacteria. Evidence supports that xylitol is noncariogenic, exhibits a dose- and frequency-dependent effect on dental plaque and streptococci mutans, and is safe. Thus, chewing xylitol ( $2 \mathrm{~g}$ of xylitol/socket) or polyols after each meal (three times daily) for 10-20 min increases the production of stimulated saliva, which has higher phosphate and calcium concentrations than 
non-stimulated saliva [7]. Sengun reported that xylitol lozenges significantly decreased the acidity of dental plaque in fixed orthodontic appliance patients. It helped neutralize the acidity of dental plaque after sucrose consumption in patients undergoing fixed orthodontic treatment [32].

\subsection{Pit and fissure sealants}

There is evidence to support that bonded resin barriers such as pit and fissure sealants may protect against the development of WSL. Filled resin sealants such as Pro Seal (Reliance Orthodontic Products, Itasca, IL, USA) may have the potential to provide even more excellent protection as a physical barrier because of their increased wear resistance compared with unfilled resin sealants. Still, their removal after orthodontic treatment can be tedious and requires the use of a high-speed rotary instrument [33]. Ultraseal XT Plus sealant showed a significant reduction in enamel demineralization during fixed orthodontic treatment and should be considered for use to reduce white spot lesions. This highly filled light-cured sealant effectively sealed the enamel surfaces adjacent to orthodontic brackets, resisted mechanical abrasion, and remained well-attached. The DIAGNOdent may be useful for evaluating the severity, progression, and depth of white spot lesions during orthodontic treatment [34].

\subsection{Microabrasion}

Microabrasion consists of chemical and mechanical processing of the enamel surface by applying an abrasive slurry of $6.6 \%$ (Opalustre) or $6 \%$ (Whiteness RM) hydrochloric acid with a brush. Microabrasion is a helpful method for the treatment of post-orthodontic WSLs [35].

\subsection{Resin Infiltration}

Resin infiltration of incipient carious lesions is a relatively new approach that shows the possible ability to improve the appearance of WSL. The idea behind resin infiltration is that the porous nature of active WSL allows a low-viscosity resin to permeate into the previously demineralized enamel matrix and fill in many of the voids with resin rather than air or water. Resin infiltration creates a refractory index that is more similar to healthy enamel. The result is an improvement in the appearance of the lesion [36]. Icon (DMG America, Englewood, NJ, USA) is currently the only product on the market that uses this approach. The clinical protocol involves etching of WSL with $15 \%$ hydrochloric acid for 2 minutes under rubber dam isolation, followed by thorough rinsing, desiccation of the enamel lesion with an ethanol drying agent, and then the application of the very low-viscosity resin, removal of gross excess, and light-curing for 40 seconds. This approach seems more successful in partially arrested lesions [36]. A comparative study by Annapurna Kannan showed that Clinpro ${ }^{\mathrm{TM}}$ XT varnish showed significantly better improvement than Icon ${ }^{\circledR}$ resin infiltration in restoring the colour and lightness of the WSLs at 3 and 6 months. The fluorescence loss significantly recovered with both the methods between immediate application and at six months [37].

\subsection{Antiseptics}

Chlorhexidine is the most used antiseptic in dentistry. It has proved very effective in controlling and managing biofilms in gingivitis. It is usually available as mouthwashes, gels, or varnishes [7]. It affects cariogenic flora and reduces streptococci mutans counts. Chlorhexidine varnishes are more effective than gels and mouthwashes. Various studies have shown the efficacy of chlorhexidine varnishes in reducing the prevalence of caries during orthodontic treatment, while others have not demonstrated the effectiveness of a varnish of $40 \%$ chlorhexidine [36].

\subsection{Lasers}

The application of Lasers increases enamel microhardness and resistance to acid attack. The principal laser usually used in preventive dentistry includes argon lasers, CO2, Nd-YAG, and erbium YAG [38]. Irradiation of enamel with argon laser beams decreases the amount of demineralization up to 30\%-50\%. Kim et al. reported that, apart from reducing enamel demineralization, laser beams lowered the dissolution threshold $\mathrm{pH}$ value [39]. Laser beams resulted in changes in surface morphology by improvement in enamel crystallinity but maintained an intact enamel surface. The application of argon laser beams (488 nm) significantly decreased the mean lesion depth compared to visible light controls, supporting that irradiation with argon laser beams might prevent the development of WSLs during treatment [40].

\subsection{Bleaching}

Khoroushi et al. showed in an in vitro study that a 
gentle, non-invasive bleaching procedure by incorporating three different biomaterials, including nanoBAG, nano-hydroxyapatite, and nano-amorphous calcium phosphate, into bleaching agents might mitigate the adverse effects of tooth bleaching and prevent the irreversible changes in the enamel surface [41]. This treatment modality should be reserved for patients with good oral hygiene to mask inactive lesions when natural remineralization is not complete [42].

\section{Conclusion}

Damage to dental enamel is one of the common complications of fixed orthodontic treatment. The responsibility of an orthodontist is to minimize the risk of the patient having decalcification as a consequence of orthodontic treatment by educating and motivating the patients for excellent oral hygiene practice.

During and after orthodontic treatment, prophylaxis with topical fluoride application should be used, highfluoride toothpaste, fluoride mouthwashes, gels, and varnishes, especially for individuals at high risk of caries. Ultimately, although scientists and/or clinicians may discover new understanding, develop new technologies and products, but it's the responsibility of patients and orthodontists to promote and use new materials which help in maintaining enamel surface integrity.

Conflicts of interest: Authors declared no conflicts of interest.

\section{Financial support: None}

\section{References}

1. Arhun N, Arman A. Effects of orthodontic mechanics on tooth enamel: a review. In Seminars in Orthodontics 2007;13(4):281-291. https://doi.org/10.1053/ j.sodo.2007.08.009

2. Roopa KB, Pathak S, Poornima P, Neena IE. White spot lesions: A literature review. J Pediatr Dent. 2015;3(1):1-7. $\quad$ https://doi.org/10.4103/2321$\underline{6646.151839}$

3. Khoroushi M, Kachuie M. Prevention and treatment of white spot lesions in orthodontic patients. Contemp Clin Dent. 2017;8(1):11. https://doi.org/10.4103/ ccd.ccd $216 \quad 17$

4. Abou Neel EA, Aljabo A, Strange A, Ibrahim S, Coathup M, Young AM, Bozec L, Mudera V. Demineralization-remineralization dynamics in teeth and bone. Int J Nanomed. 2016;11:4743. https://
doi.org/10.2147/IJN.S107624

5. Dowd F. Saliva and dental caries. Dent Clin North Am. 1999;43(4):579-597.

6. Bishara SE, Ostby AW. White spot lesions: Formation, prevention, and treatment. Semin Orthod. 2008;14:174-82. $\quad$ https://doi.org/10.1053/ j.sodo.2008.03.002

7. Heymann GC, Grauer D. A contemporary review of white spot lesions in orthodontics. J Esthet Restor Dent. 2013;25(2):85-95. https://doi.org/10.1111/ jerd.12013

8. Nascimento PL, Fernandes MT, Figueiredo FE, Fariae-Silva AL. Fluoride-releasing materials to prevent white spot lesions around orthodontic brackets: a systematic review. Braz Dent J. 2016;27:101-7. https:// doi.org/10.1590/0103-6440201600482

9. Benson PE, Parkin N, Dyer F, Millett DT, Furness S, Germain P. Fluorides for the prevention of early tooth decay (demineralised white lesions) during fixed brace treatment. Cochrane Database Syst Rev. 2013;12:CD003809. https:// doi.org/10.1002/14651858.CD003809.pub3

10. Geiger AM, Gorelick L, Gwinnett AJ, Benson BJ. Reducing white spot lesions in orthodontic populations with fluoride rinsing. Am J Orthod Dentofacial Orthop. 1992;101(5):403-7. https://doi.org/10.1016/0889-5406(92)70112-N

11. Boyd RL. Comparison of three self-applied topical fluoride preparations for control of decalcification. Angle Orthod. 1993;63(1):25-30.

12. Azarpazhooh A, Main PA. Fluoride varnish in the prevention of dental caries in children and adolescents: a systematic review. J Can Dent Assoc. 2008;74(1): 73-79.

13. Demito CF, Bowman SJ, Ramos AL. The effectiveness of a fluoride varnish in preventing the development of white spot lesions. World J Orthod. 2006;7 (2):138-144.

14. Sita Ramaraju DV, Alla RK, Alluri VR, Raju MA. A review of conventional and contemporary luting agents used in dentistry. Am J Mater Sci Eng. 2014;2 (3):28-35. https://doi.org/10.12691/ajmse-2-3-1

15. Neti B, Sayana G, Muddala L, Mantena SR, Yarram A, Harsha GV. Fluoride releasing restorative materials: a review. Int J Dent Mater. 2020;21:19-23. https://doi.org/10.37983/IJDM.2020.2104

16. Sudjalim TR, Woods MG, Manton DJ, Reynolds EC. Prevention of demineralization around orthodontic brackets in vitro. Am J Orthod Dentofacial Orthop. 2007;131(6):705-e1. https://doi.org/10.1016/ j.ajodo.2006.09.043

17. Navyasri K, Alla RK, Vineeth G, Suresh Sajjan MC. An overview of dentin bonding agents. Int J Dent Mater.2019;1(2): 60-67. https://doi.org/10.37983/ IJDM.2019.1204

18. Manfred L, Covell DA, Crowe JJ, Tufekci E, Mitchell JC. A novel biomimetic orthodontic bonding agent 
helps prevent white spot lesions adjacent to brackets. Angle Orthod. 2013;83(1):97-103. https:// doi.org/10.2319/110811-689.1

19. Mattick CR, Mitchell L, Chadwick SM, Wright J. Fluoride-releasing elastomeric modules reduce decalcification: a randomized controlled trial. J Orthod. 2014;28(3): 217-220. $\quad$ https://doi.org/10.1093/ ortho/28.3.217

20. Hedayati Z, Sadeghi S, Derakhshandeh A. The Effect of Fluoride-releasing Elastomeric Chains on Streptococcus mutans Levels in Saliva and Dental Plaque in Orthodontic Patients. J Islam Dent Assoc Iran. 2013;25(2):80-6.

21. Arhun N, Arman A, Cehreli SB, Arıkan S, Karabulut E, Gülşahı K. Microleakage beneath ceramic and metal brackets bonded with a conventional and an antibacterial adhesive system. Angle Orthod. 2006;76 (6):1028-34. https://doi.org/10.2319/101805-368

22. Jasso-Ruiz I, Velazquez-Enriquez U, ScougallVilchis RJ, Morales-Luckie RA, Sawada T, Yamaguchi R. Silver nanoparticles in orthodontics, a new alternative in bacterial inhibition: in vitro study. Prog Orthod. 2020;21(1):1-8. https://doi.org/10.1186/ s40510-020-00324-6

23. Wang X, Wang B, Wang Y. Antibacterial orthodontic cement to combat biofilm and white spot lesions. Am J Orthod Dentofacial Orthop. 2015;148(6):974-81.

24. Jabi S, Diwedi S, Upadhyay V, Abdullah A, Sarfaraj M, Mishra A. An in vitro study to evaluate and compare the remineralizing potential among Casein Phosphopeptide-amorphous Calcium Phosphate (CPPACP) with fluoride and surface pre-reacted glass (SPRG) fillers using quantitative analysis.: Comparison between two types of remineralizing agents. Int $\mathrm{J}$ Dent Mater. 2021;3(3):70-5. https://doi.org/10.37983/ IJDM.2021.3301

25. Wen-Dan H, Ying-Zhi L, Yuan-Yuan X, Dong C. Study on application of CPP-ACP on tooth mineralization during orthodontic treatment with fixed appliance. Shanghai J Stomatol. 2010;19:140-3.

26. Pithon MM, Baião FS, Sant'Anna LI, Tanaka OM, Cople-Maia L. Effectiveness of casein phosphopeptide-amorphous calcium phosphate-containing products in the prevention and treatment of white spot lesions in orthodontic patients: A systematic review. J Investig Clin Dent. 2019;10(2):e12391. https:// doi.org/10.1111/jicd.12391

27. Robertson MA, Kau CH, English JD, Lee RP, Powers J, Nguyen JT. MI paste plus to prevent demineralization in orthodontic patients: A prospective randomized controlled trial. Am J Orthod Dentofacial Orthop. 2011;140:660-8.

28. Pithon MM, Dos Santos MJ, Andrade CS, Leão Filho $\mathrm{JC}$, Braz AK, de Araujo RE, et al. Effectiveness of varnish with CPP-ACP in prevention of caries lesions around orthodontic brackets: An OCT evaluation. Eur J Orthod. 2015;37:177-82.
29. Zahradnik RT, Magnusson I, Walker C, et al. Preliminary assessment of safety and effectiveness in humans of ProBiora3, a probiotic mouthwash. J Appl Microbiol 2009;107(2):682-90.

30. Lin TH, Lin CH, Pan TM. The implication of probiotics in the prevention of dental caries. Appl Microbiol Biotechnol. 2018;102(2):577-86.

31. Chaturvedi S, Jain U. Importance of probiotics in orthodontics. J Orofacial Res. 2015:99-103. https:// doi.org/10.5005/jp-journals-10026-1190

32. Sengun A, Sari Z, Ramoglu SI, Malkoç S, Duran I. Evaluation of the dental plaque $\mathrm{pH}$ recovery effect of a xylitol lozenge on patients with fixed orthodontic appliances. Angle Orthod. 2004;74:240-4.

33. Clark TJ. The efficacy of ProSeal ${ }^{\mathrm{TM}}$, SeLECTDefense $^{\mathrm{TM}}$, OrthoCoat ${ }^{\mathrm{TM}}$, and Biscover LV ${ }^{\mathrm{TM}}$ resin sealants on the prevention of enamel demineralization and white spot lesion formation. Thesis submitted to the University of IOWA, USA, 2013.

34. Benham AW, Campbell PM, Buschang PH. Effectiveness of pit and fissure sealants in reducing white spot lesions during orthodontic treatment: A pilot study. Angle Orthod. 2009;79(2):338-45. https:// doi.org/10.2319/022808-30.1

35. Croll TP. Enamel microabrasion for removal of superficial demineralization and decalcification defects. J Am Dent Assoc 1990;120(4):411-5. https:// doi.org/10.14219/jada.archive.1990.0127

36. Dawes C, Macpherson LM. Effects of nine different chewing-gums and lozenges on salivary flow rate and pH. Caries Res 1992;26(3):176-82.

37. Kannan A, Padmanabhan S. Comparative evaluation of Icon ${ }^{\circledR}$ resin infiltration and Clinpro ${ }^{\mathrm{TM}}$ XT varnish on colour and fluorescence changes of white spot lesions: a randomized controlled trial. Prog Orthod. 2019;20(1):1-8. https://doi.org/10.1186/s40510-019$\underline{0276-\mathrm{y}}$

38. Paul P, Duvvuri SR, Alla RK, Rajasigamani K. Evaluation of shear bond strength of stainless steel brackets bonded to ceramic crowns etched with Er; Cr: YSGG laser and hydrofluoric acid: an in vitro study. J Adv Med Med Res. 2015;11:550-60.

39. Kim S, Kim EY, Jeong TS, Kim JW. The evaluation of resin infiltration for masking labial enamel white spot lesions. Int J Paediatr Dent 2011;21(4): 241-8.

40. Duvvaru LS, Jain V, Mittal S, Alla RK. The Shadow Capturers that Revolutionised Radiology: Image Receptors. Trends Biomater Artif Organs. 2018;32 (3):128-32.

41. Kannan Sabapathy D, Naveed N. Treatment of White Spot Lesions Post Fixed Orthodontic Therapy. Eur J Mol Clin Med. 2020;7(8):1824-9.

42. Ranganayakulu I, Varma DP, Priya CV P, Ram RR, Viswanadh KA, Harsha GD. Effect of Adhesive Boosters on Bond Strength of Bleached Teeth in Orthodontic Bonding. J Indian Orthod Soc. 2021:03015742211004431. 